\title{
Demographic Profile of p16 Immunopositive and HPV DNA PCR Positive Oral Squamous Cell Carcinoma in a Large Cohort of Indian Patients
}

\author{
Farhat Naz ${ }^{1}$, Hitesh Verma ${ }^{2}$, Nadeem Tanveer ${ }^{3}$, Arava Kumar Sudheer ${ }^{4}$, Aanchal \\ Kakkar $^{4}$, Pranay Tanwar ${ }^{1 *}$
}

\begin{abstract}
Background: The Indian subcontinent has the highest incidence of oral cavity squamous cell carcinoma in the world. The high incidence of tobacco chewing habit with or without smoking has been found to be the chief culprit. However in a minor subset of patients Human Papilloma Virus may play a role. Materials and Methods: A total of 800 cases of Oral squamous cell carcinoma were included in the study. The patients were given a questionnaire comprising of questions about demographic details and habits. The biopsy samples were routinely processed for immunohistochemistry for p16 (E6H4 clone, CINtec histology, Roche diagnostics). Cases with $2+/ 3+$ positive nuclear staining with more than $75 \%$ cells immunopositive were taken as p16 immunopositive as per the AJCC criteria and were further subjected to HPV DNA PCR for which DNA was extracted from the formalin fixed paraffin embedded tissue. Results: Out of 800 OSCC cases 139 (17.37\%) showed p16 immunopositivity by AJCC criteria. Out of these, 104 (104/139, 74.8\%) cases were positive by HPV DNA PCR for HPV-16/18. Following patient characteristics were associated with a higher proportion of 16 and HPV DNA positivity-urban residence, vegetarian diet, illiteracy, graduate or higher education. No correlation was noted with gender, tobacco smoking or chewing habits, religion, occupation or site of tumor. The p16 immunopositivity was higher in the younger age group with no tobacco habits. Conclusion: A significant proportion of OSCC cases in India are associated with HPV infection. A higher percentage of p16 immunopositivity amongst younger patients with no tobacco habits points towards a distinct subset of patients in whom HPV may be the chief culprit and not just playing a supporting role.
\end{abstract}

Keywords: Oral squamous cell carcinoma- human papilloma virus- p16 immunopositive- HPV DNA PCR

Asian Pac J Cancer Prev, 23 (2), 529-536

\section{Introduction}

The success story of drastic reduction in the incidence and prevalence of HPV related cervical squamous cell carcinoma by concerted efforts of health care providers aimed at screening, early detection and vaccination has prompted a search for other HPV related cancers. Foremost amongst these malignancies is the head and neck squamous cell carcinoma.

The early studies on head and neck squamous cell carcinomas and HPV did not make a distinction between Oral Squamous Cell Carcinoma (OSCC) and Oropharyngeal squamous cell carcinoma (OPSCC) and treated them as one entity. However, slowly the realization set in that these are vastly different entities with respect to their prognosis, treatment and association with HPV (Panarese et al., 2019). The association of HPV with a subset of OPSCC with better prognosis has been accepted by American Joint Committee on Cancer (AJCC) and HPV status by p16 immunohistochemistry is now evaluated for OPSCC staging (Kato et al., 2020). However for OSCC it is largely believed that only a small percentage of cases have an association with HPV. Several conflicting reports on the prevalence of HPV infection in OSCC on small cohorts of patients have only added to the confusion (Laco et al., 2012; Maléŕová et al., 2020; Wang et al., 2017; Palve et al., 2018)

Since OSCC is the leading type of cancer prevalent in the Indian subcontinent, even a minor component (10-20\%) will merit public health importance. The other aspect of virus related malignancies is that the overall percentages and prevalence in the population is fluid and keeps changing with time. World over the prevalence of HPV related OPSCC is on the rise. While smoking and 
tobacco related OPSCC has decreased over the last decade, the incidence of HPV related OPSCC has increased in the younger non-smoking population (Mena et al., 2020). Hence it is logical to expect an increase in the incidence of HPV related OSCC as well.

The Indian subcontinent has the highest incidence of oral cavity squamous cell carcinoma in the world. The high incidence of tobacco chewing habit with or without smoking has been found to be the chief culprit (Kreimer et al., 2005; Koppikar et al., 2005). However in a minor subset of patients Human Papilloma Virus may play a role. Oral cavity is easily accessible for examination still early detection has been a challenge. A multistep carcinogenesis model is more likely to explain the heterogeneous clinical features and the fact that not all persons chewing tobacco, betelnut or smoking bidi or cigarette gets the cancer (Koppikar et al., 2005). Lack of micronutrients ,poor oral hygiene and HPV can act as cofactors in the development of oral cancers.

This is the first study from India comparing the p16 immunopositivity and HPV DNA status in large sample size of 800 patients of OSCC undergoing treatment at a tertiary care centre.

\section{Materials and Methods}

A total of 800 cases of Oral squamous cell carcinoma attending the Out Patient clinic of Ear Nose and Throat department of a tertiary care hospital were included in the study. The patients were asked to fill the consent form to participate in the study and were given a questionnaire which was explained to them in simple language. The questionnaire comprised of questions about demographic details and habits.

The biopsy samples were routinely processed for hematoxylin and eosin staining and immunohistochemistry for p16 (E6H4 clone, CINtec histology, Roche diagnostics) was performed on 3 micron sections taken on lysine coated slides. A known p16 immunopositive case of cervical squamous cell carcinoma was taken as positive control. Cases with $2+/ 3+$ positive nuclear staining with more than $75 \%$ cells immunopositive were taken as p16 immunopositive as per the AJCC (American Joint Committee on Cancer)criteria and were further subjected to HPV DNA PCR (Machczyński et al., 2020).

Genomic DNA was extracted from the formalin fixed paraffin embedded tissue by using Promega Reliaprep FFPE gDNA Miniprep system- A2352 (Promega, Madison, WI, USA) kit following the manufacturer's protocol (Gayatree et al., 2020; Shelton et al., 2017). Four to five ribbons of $10 \mu \mathrm{m}$ thick tissue sections for each sample were collected for DNA extraction. After processing, the purified eluted DNA of each sample was evaluated for its concentration yield in suspension using Nanodrop (Thermofisher). The DNA yield was measured in $\mathrm{ng} / \mu \mathrm{L}$ at absorbance $260 \mathrm{~nm}$. The 260/280 absorbance ratio determined the DNA purity and presence of contaminants in the extracted DNA. And then extracted DNA was stored at $-20^{\circ} \mathrm{C}$ for further testing.

Detection of HPV DNA through qPCR was performed by using Hybribio- 14 High-risk HPV with 16/18
Genotyping Real-time PCR Detection kit following the manufacturer's instructions (Liu et al., 2010). The HPV detection kit had features of specific detection of 2 high-risk HPV genotypes: HPV 16 and HPV 18 with high sensitivity and specificity $>95 \%$. The kit also detected other high-risk HPV types: HPV 31, 33, 35, 39, 45, 51, $52,56,58,59,66$, and 68 however they were all clubbed into one category- "Other HPV types". It could not specify which of the other HPV types was present in the sample. The probes for signal collection were FAM/HEX/ROX, HEX for HPV16, ROX for HPV18, and FAM for other 12 high-risk HPV types mentioned above. Briefly, the extracted DNA test samples and PCR master mix were thawed at room temperature. A total volume of $18 \mu \mathrm{L}$ premix was prepared consisted $17.5 \mu \mathrm{L}$ of PCR Master Mix and $0.5 \mu \mathrm{L}$ of DNA Taq Polymerase (per PCR reaction well) in 96 well plate. A volume of $2 \mu \mathrm{L}$ of extracted DNA test sample was added in each well gently and evenly mixed each reagent by pipetting. The mixed reagents and samples were centrifuged briefly to collect the contents. The cellular internal control presents to monitor the entire process. A positive control and a negative control were run with each set of samples. The positive control was to demonstrate the efficiency and negative control was to indicate if the PCR reagents or environment was contaminated. The following thermal cycling programme was run in qPCR machine for the prepared sample. DNA Pre-denaturing- $95^{\circ} \mathrm{C}, 10 \mathrm{~min}, 1$ cycle, (Denaturing- $95^{\circ} \mathrm{C}$, $15 \mathrm{sec}$, Anneal/ Extension- $60^{\circ} \mathrm{C}$, $60 \mathrm{sec}$ together 45 cycles), termination- $38^{\circ} \mathrm{C}, 5 \mathrm{sec}$ and (collect FAM, HEX, ROX and Cy5 signals). The $\mathrm{Ct}$ value was given with the manual for considering sample positive or negative. If the $\mathrm{Ct}$ value of a sample was $\leq 40$ it was considered positive.

The p16 immunopositivity and HPV PCR test results were cross tabulated with the demographic features and appropriate statistical tests of significance were performed.

The study was given clearance by the Institute Ethics Committee for Human Research Ref. no. IEC-286/01.06.2018, RP-17/2018

The research was supported by grant from Ministry of Health and Family Welfare (Department of Health Research) : Grant number- File No.R.12013/03/2018-HR

\section{Results}

Out of 800 OSCC cases 139 (139/800, 17.37\%) cases showed p16 immunopositivity by AJCC criteria (Figure 1). Out of these, $104(104 / 139,74.8 \%)$ cases were positive by HPV DNA PCR for HPV-16/18. Co-infections of other high risk HPV with HPV-16/18 were observed in $34(34 / 104,32.7 \%)$ of positive cases. Thirty two of these co-infections were seen with HPV 18 and two were seen with combined HPV 16 and 18 infections. None of the cases was positive for "other high risk HPV" alone. The breakup of HPV-16/18 positive cases was as follows-Forty eight $(46.2 \%)$ cases were positive for only for HPV-16, 20 cases $(19.2 \%)$ were positive for both HPV 16 and 18, and 36 cases $(34.6 \%)$ were positive only for HPV-18. The age of the patients ranged from 21 to 80 years, and mean age was 45.2 years. Most of the OSCC patients were in the age group of $40-60$ years i.e. $482 / 800(60.3 \%)$. 
Majority of the cases showing positivity for $\mathrm{p} 16$ were also from the age group of 40-60 years i.e.80/139 (57.6\%). Out of 690 patients who had a tobacco smoking habit, 125 $(18.1 \%)$ and $88(12.7 \%)$ cases were positive for $\mathrm{p} 16$ and HPV PCR respectively. Similar outcomes were noted for tobacco /betel nut chewing as well (Table 1).

A total of $61 / 480(12.7 \%)$ rural cases were p16 positive while $78 / 320(24.3 \%)$ urban cases were positive. p16 and HPV DNA PCR Positive of OSCC

The difference was statistically significant $(\mathrm{p}<.001)$. Similar trend was noted for HPV positivity by PCR as well (Table 1) There was some correlation between the educational status and p16 immunopositivity with the extreme groups of illiterate and graduate and beyond patients showing higher p16 immunopositivity than the others. $(\mathrm{p}=.03)$ However the correlation was not significant for HPV PCR.

Table 1. Demographic Details and Habits of OSCC Cases Immunopositive for p16 and Positive for HPV DNA 16/18 by PCR.

\begin{tabular}{|c|c|c|c|c|c|}
\hline Parameters & $\begin{array}{l}\text { Number of } \\
\text { OSCC cases } \\
(\%)\end{array}$ & $\begin{array}{l}\text { Number of p16 } \\
(3+/ 2+) \text { positive } \\
\text { cases }(\%)\end{array}$ & $\begin{array}{l}\mathrm{P} \text { value at } 0.05 \\
\text { significance level } \\
\text { (Chi Square Test) }\end{array}$ & $\begin{array}{c}\text { Number of HPV } \\
\text { DNA }(16 / 18) \\
\text { positive cases }(\%)\end{array}$ & $\begin{array}{l}\mathrm{P} \text { value at } 0.05 \\
\text { significance level } \\
\text { (Chi Square Test) }\end{array}$ \\
\hline Total & $800(100)$ & $139(17.4)$ & & $104(13)$ & \\
\hline Gender & & & 0.43 & & 0.5 \\
\hline Male & $701(87.6)$ & $119(16.9)$ & & $89(12.7)$ & \\
\hline Female & $99(12.4)$ & $20(20.2)$ & & $15(15.2)$ & \\
\hline Age & & & 0.74 & & 0.7 \\
\hline$\leq 40$ & $189(23.6)$ & $36(19.0)$ & & $28(14.8)$ & \\
\hline $40-60$ & $482(60.3)$ & $80(16.6)$ & & $60(12.4)$ & \\
\hline$\geq 60$ & $129(16.1)$ & $23(17.8)$ & & $16(12.4)$ & \\
\hline Tobacco Habits & & & 0.96 & & 0.57 \\
\hline None & $110(13.8)$ & 21(19.1) & & $18(16.3)$ & \\
\hline Tobacco Smoking & $690(86.3)$ & $125(18.1)$ & & $88(12.7)$ & \\
\hline Tobacco/Betel nut chewing & $660(82.5)$ & $119(18.0)$ & & $85(12.8)$ & \\
\hline Residence & & & $<.001$ & & 0.002 \\
\hline Rural & $480(60)$ & $61(12.7)$ & & $48(10)$ & \\
\hline Urban & $320(40)$ & $78(24.3)$ & & $56(17.5)$ & \\
\hline Religion & & & 0.39 & & 0.64 \\
\hline Non-Muslim & $659(82.3)$ & $111(16.8)$ & & $84(12.7)$ & \\
\hline Muslim & 141(17.6) & $28(19.8)$ & & $20(14.2)$ & \\
\hline Marital Status & & & 0.34 & & 0.64 \\
\hline Married & $761(95.1)$ & $130(17.1)$ & & $98(12.8)$ & \\
\hline Unmarried & $39(4.8)$ & $9(23.1 \%)$ & & $6(15.4)$ & \\
\hline Qualification & & & 0.03 & & 0.8 \\
\hline Illiterate & $138(17.3)$ & $28(20.2)$ & & $21(15.2)$ & \\
\hline Primary & $150(18.7)$ & $19(12.6)$ & & $19(12.6)$ & \\
\hline Secondary & $312(39.2)$ & $46(14.7)$ & & $37(11.8)$ & \\
\hline Grad/Post grad & $200(25.0)$ & $46(23.0)$ & & $27(13.5)$ & \\
\hline Occupation & & & 0.14 & & 0.4 \\
\hline Unskilled & $279(34.9)$ & $55(19.7 \%)$ & & $30(10.8)$ & \\
\hline Semiskilled & $384(48.0)$ & $57(14.8 \%)$ & & $54(14.1)$ & \\
\hline Skilled & $75(9.4)$ & $18(24 \%)$ & & $9(12)$ & \\
\hline House wife & $62(7.7)$ & $9(14.5 \%)$ & & $11(17.7)$ & \\
\hline Family Members & & & 0.1 & & 0.09 \\
\hline$\leq 2$ & $42(5.2)$ & $9(21.4)$ & & $4(9.5)$ & \\
\hline 3 to 5 & $462(57.7)$ & $92(19.9)$ & & $72(15.6)$ & \\
\hline 6 to 10 & $284(35.5)$ & $38(13.4)$ & & $27(9.5)$ & \\
\hline$\geq 11$ & $12(1.5)$ & $0(0.00)$ & & $1(9.1)$ & \\
\hline Dietary Habits & & & $<.001$ & & 0.006 \\
\hline Vegetarian & $225(28.1)$ & $63(28)$ & & $41(18.2)$ & \\
\hline Both (Veg/Non veg) & $575(71.8)$ & $76(13.2)$ & & $63(10.9)$ & \\
\hline
\end{tabular}




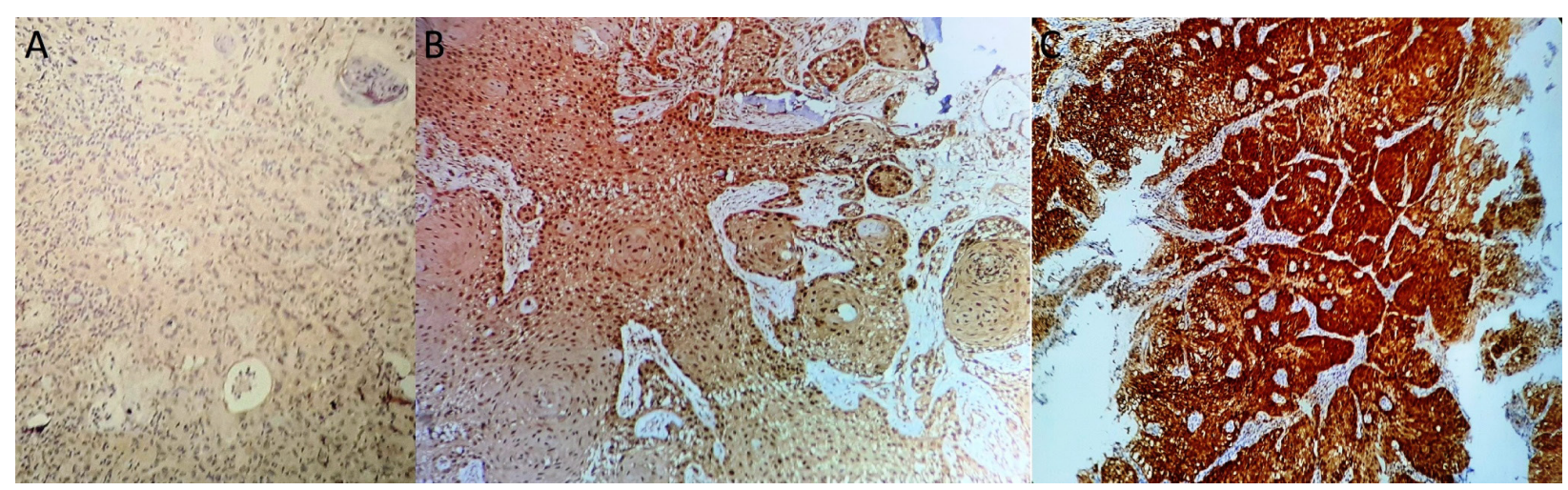

Figure 1. Different Intensities of p16 Immunostaining in OSCC Cases-A (100x)-1+ intensity (Taken as negative) B (200x)-2+ intensity C (200x)-3+ intensity. Both $2+$ and $3+$ intensity in at least $75 \%$ cells was taken as positive staining.

Table 2. Site Wise Data for p16 and HPV DNA Positive OSCC Cases

\begin{tabular}{lccc}
\hline Site & $\begin{array}{c}\text { Number of OSCC } \\
\text { cases }(\%) / 800\end{array}$ & $\begin{array}{c}\text { Number of p16 (3+/2+) } \\
\text { positive cases }(\%) / 139\end{array}$ & $\begin{array}{c}\text { Number of HPV DNA (16/18) } \\
\text { positive cases }(\%) / 104\end{array}$ \\
\hline Lips & $20(2.5)$ & $3(15)$ & $2(10)$ \\
Buccal Mucosa & $272(34.0)$ & $47(17.3)$ & $33(12.1)$ \\
2/3rd of tongue & $302(37.7)$ & $44(14.6)$ & $34(11.3)$ \\
Soft palate & $78(9.7)$ & $13(16.7)$ & $10(12.8)$ \\
Hard palate & $30(3.7)$ & $6(20)$ & $6(20)$ \\
Retromolar trigone & $8(1.0)$ & $6(75)$ & $5(62.5)$ \\
Gingivobuccal sulcus & $14(1.7)$ & $8(57.1)$ & $7(50)$ \\
Floor of mouth & $25(3.1)$ & $5(20)$ & $2(8)$ \\
Alveolus & $51(6.3)$ & $5(10)$ & $5(9.8)$ \\
\hline
\end{tabular}

P value (at 0.05 significance level) for p16 immunopositivity for buccal mucosa, anterior two third of tongue and other sites=.22 (Chi Square Test); $P$ value (at 0.05 significance level) for $\mathrm{p}$ HPV positivity for buccal mucosa, anterior two third of tongue and other sites $=.20$ (Chi square Test)

Patients with vegetarian dietary habits had a higher chance of being p16 or HPV PCR positive as compared to patients consuming both vegetarian and non-vegetarian food. $(\mathrm{p}<0.001$ and $\mathrm{p}=0.006)$

No statistically significant correlation was found between p16 or HPV PCR positivity and gender, age,

Table 3. Cross Tabulation of Age, Gender, Site and Tobacco Related Habits in OSCC Patients

\begin{tabular}{lcccccccccccccccc}
\hline Age & \multicolumn{3}{c}{ Gender } & \multicolumn{1}{c}{ OSCC (p16+ve) } & \multicolumn{4}{c}{ Site } & \multicolumn{4}{c}{ Habit } \\
OSCC (p16+ve) & \multicolumn{1}{c}{ Ors } & M & F & L & BM & T & SP & HP & RT & GS & FM & A & ST & CT & NH \\
\hline $25-35$ & $122(23)$ & $9(1)$ & $2(0)$ & $44(8)$ & $61(13)$ & $5(1)$ & $3(1)$ & $4(0)$ & $7(1)$ & $3(1)$ & $2(0)$ & $53(12)$ & $88(12)$ & $8(6)$ \\
$36-45$ & $211(34)$ & $10(6)$ & $3(0)$ & $78(15)$ & $87(18)$ & $11(2)$ & $7(0)$ & $14(1)$ & $16(2)$ & $4(0)$ & $11(2)$ & $99(18)$ & $160(21)$ & $21(10)$ \\
$46-55$ & $185(30)$ & $37(7)$ & $6(2)$ & $75(15)$ & $66(5)$ & $21(5)$ & $15(1)$ & $15(2)$ & $6(4)$ & $6(2)$ & $12(1)$ & $158(21)$ & $158(21)$ & $15(5)$ \\
$56-65$ & $133(29)$ & $23(2)$ & $5(2)$ & $41(11)$ & $39(4)$ & $24(7)$ & $10(3)$ & $7(2)$ & $10(0)$ & $4(0)$ & $16(2)$ & $75(14)$ & $89(14)$ & $37(11)$ \\
$66-75$ & $44(4)$ & $6(3)$ & $1(0)$ & $16(2)$ & $11(2)$ & $6(1)$ & $2(0)$ & $3(1)$ & $3(1)$ & $3(0)$ & $5(0)$ & $25(2)$ & $38(2)$ & $12(5)$ \\
$76-85$ & $6(0)$ & $4(0)$ & $1(0)$ & $1(0)$ & $4(0)$ & $1(0)$ & $1(0)$ & $0(0)$ & $1(0)$ & $0(0)$ & $1(0)$ & $3(0)$ & $6(0)$ & $3(0)$ \\
\hline
\end{tabular}

The figures within brackets shows number of cases positive for p16 ( M, Male; F, Female; L, Lip; BM, Buccal Mucosa; T, Tongue; SP, Soft palate; HP, Hard Palate; RT, Retromolar Trigone; GS, Gingivobuccal sulcus; FM, Floor of the Mouth; A,Alveolus; ST, Smoking tobacco; CT, chewing tobacco; NH, No habit).

Table 4. Distribution of OSCC, p16 Positive and HPV DNA Positive Cases According to the Degree of Differentiation

\begin{tabular}{lccc}
\hline Differentiation & $\begin{array}{c}\text { Number of OSCC cases } \\
(\%) / 800\end{array}$ & $\begin{array}{c}\text { Number of p16(3+/2+) } \\
\text { positive cases }(\%) / 139\end{array}$ & $\begin{array}{c}\text { Number of HPV DNA (16/18) positive } \\
\text { cases }(\%) / 104\end{array}$ \\
\hline Well & $146(18.2)$ & $22(16.2)$ & $20(19.2)$ \\
Moderate & $618(77.2)$ & $109(79.5)$ & $81(77.8)$ \\
Poor & $36(4.5)$ & $6(4.3)$ & $4(3.8)$ \\
\hline
\end{tabular}

$\mathrm{P}$ value (at 0.05 significance level) for $\mathrm{p} 16$ immunopositivity for Well, Moderate and Poorly differentiated tumors $=0.76$ (Chi Square Test); P value (at 0.05 significance level) for HPV positivity for Well, Moderate and Poorly differentiated tumors=0.92 (Chi square Test) 
Table 5. Distribution of TNM Staging of OSCC, p16 and HPV DNA Positive Cases According to the UICC ( $7^{\text {th }}$ Edition) Staging of Carcinoma of Oral Cavity; TNM, Tumor-Lymph node-Metastasis

\begin{tabular}{lcccc}
\hline TNM Classification & Clinical Stages & $\begin{array}{c}\text { Number of OSCC } \\
\text { Patients }(\%) / 800\end{array}$ & $\begin{array}{c}\text { Number of p16 (3+/2+) } \\
\text { positive cases }(\%) / 139\end{array}$ & $\begin{array}{c}\text { Number of HPV DNA (16/18) } \\
\text { positive cases }(\%) / 104\end{array}$ \\
\hline T1N0M0 & I & $29(3.6)$ & $4(2.8)$ & $3(2.8)$ \\
T2N0M0 & II & $44(5.5)$ & $9(6.4)$ & $7(6.7)$ \\
T1N1M0-T3N1M0 & III & $221(27.7)$ & $42(30.2)$ & $35(33.6)$ \\
T1N2M0-T4aN2cM0 & IVA & $433(54.2)$ & $73(52.5)$ & $54(51.9)$ \\
T3N3M0-T4bN3M0 & IVB & $60(7.5)$ & $9(6.4)$ & $4(3.8)$ \\
T2N2cM1-T4aN1M1 & IVC & $12(1.5)$ & $2(1.4)$ & $1(0.9)$ \\
\hline
\end{tabular}

$\mathrm{P}$ value (at 0.05 significance level) for p16 immunopositivity for different Tumor Stage $=0.94$ (Chi Square Test); P value (at 0.05 significance level) for HPV positivity for different Tumor Stage $=0.47$ (Chi Square Test)

tobacco habits, religion, marital status, occupation and number of family members.

Buccal mucosa and anterior two thirds of the tongue were the most common sites involved by OSCC (Table 2 ). There was no statistically significant difference in the p16 immunopositivity between buccal mucosa, anterior tongue and other sites. However few rare sites like retromolar trigone and gingivobuccal sulcus had a very high percentage of 16 and HPV DNA positivity. However since the number of cases included were small for these sites this result needs further validation.

On cross tabulation of age, sex, site and tobacco habits of the patients some interesting patterns were identified (Table 3). The male to female ratio of OSCC cases was higher in the younger age group and it steadily declined at older age bracket (from 21:1 in 36 to 45 age group to 1.5 in 76-85 age group). The proportion of cases affecting the posterior sites of oral cavity like soft palate and hard palate is higher in the 46 to 65 year age group (22\%) as compared to the younger age bracket $(7.8 \%$ in 26 to 45 year). The proportion of patients having no tobacco related habits steadily increases with increasing age (6.5\% in 26 to 35 year age group to $30 \%$ in $76-85$ year age group).

The p16 immunopositivity was higher in the younger age group with no tobacco habits. p16 was positive in $6 / 8$ (75\%) and 10/21 (47.6\%) OSCC cases with no tobacco habits in the age group of 25 to 35 years and $36-45$ years respectively (Table 3 ).

Based on histopathologic differentiation of tumor, most of the cases with p16 and HPV DNA positivity were found in the moderately differentiated category-109/139 (79.5\%) and 81/104 (77.8\%) respectively, followed by well and poorly differentiated category (Table 4).

The OSCC cases were classified according to the tumor-lymph node-metastasis classification of the Union for International Cancer Control, UICC (7th edition) staging of carcinoma of oral cavity. Majority of p16 and HPV positive tumors belonged to the Stage IVA (T1N2M0-T4aN2cM0)-73/139 (52.5\%) and 54/104 (51.9\%) (Table 5).

There was no correlation between the tumor stage and tumor differentiation with p16 immunopositivity or HPV positivity.

\section{Discussion}

In a large meta-analysis of 2,642 cases of oral squamous cell carcinoma Kreimer AR et al reported an overall HPV prevalence of 23.5\% (Kreimer et al., 2005). They also noted a higher prevalence in studies on Oral squamous cell carcinoma from Asia (33\%) in comparison with Europe and North and South America. Further, most of the studies were restricted by the number of cases included (between 10 and 100). The larger studies reported a lower prevalence of HPV positivity. Koppiker P et al have reported an HPV positivity of $34 \%$ on a small sample of 83 cases of oral squamous cell carcinoma from India (Koppikar et al., 2005).

P16 immunohistochemistry has been used extensively as a surrogate marker of HPV infection. Laco et al ., (2012) reported 17/48 (35\%) immunopositivity for p16 in OSCC. In another study p16 expression was upregulated in $8.3 \%$ cases of OSCC and was found to be a negative prognostic factor for OSCC (Maléřová et al., 2020). In two separate studies on 95 cases and 153 patients of OSCC, p16 was reported to be positive in $9.5 \%$ and $18 \%$ cases respectively (Wang et al., 2017; Palve et al., 2018)

On a large sample size of 800 patients of OSCC we found an overall p16 immunopositivity of $17.37 \%$ (139/800). Out of these 139 cases 104 cases $(104,800$, $13 \%$ ) were HPV PCR positive.All these cases were either positive for HPV 16 or HPV 18 or both. In addition, a coinfection with other high risk HPV types was observed in 34 of these cases. However the kit used for the study could not delineate the exact HPV type in these cases. In a study by Bouda M et al, HPV-16/18 infection was observed in $89.5 \%$ of oral squamous cell carcinoma. Non HPV-16/18 strain was found in $5.2 \%$ of cases whereas co-infection (non HPV-16/18 high risk HPV with HPV16/18) was found in 5.2\% of cases (Bouda M et al, 2000). Seraj et al., (2011) found an overall prevalence of $10 \%$ and $16 \%$ for HPV-16 and HPV -18 in oral tongue squamous cell carcinoma. The distribution of HPV subtypes shows variation with geographical location of the study and the site of the tumor studied. P16 is a cell cycle regulator and is expressed in a wide variety of normal, benign and malignant cells. Herein lies the problem of interpretation and cut offs for the purpose of identifying HPV related cancers. P16 is likely to be upregulated in non HPV pathway associated tumors as well. Due to this reason p16 
immunopositivity is usually higher than the prevalence of HPV by DNA PCR in HPV positive tumors. The positivity goes further down when HPV RNA ISH is used.

The other problem in accurately estimating the prevalence of HPV infection in oral squamous cell carcinoma is the misclassification of the site of the tumor. In advanced stages, oropharyngeal squamous cell carcinomas can be wrongly classified as oral squamous cell carcinoma thereby falsely elevating the HPV prevalence (Kreimer et al., 2005). In our study accurate documentation of the exact site of the tumor was ensured by noting down the site at the time of taking the biopsy itself and not from the histopathology requisition form.

P16 immunohistochemistry has been used as a surrogate for HPV infection but its cut off and antibody clones used have generated debate. There is a consensus now that moderate to strong immunopositivity for $\mathrm{p} 16$ in more than 75 percent of the tumor cells is an accurate predictor of HPV positivity by RNA ISH (Machczyński et al., 2020). While this cut off has been approved by AJCC for OPSCC in their guidelines, it has been used for OSCC as well (Gayatree et al., 2020). The other controversial topic is the p16 antibody clone to be used. The most widely used clone is the E6 H4 clone (CINtec histology Roche) which has given consistent results with 75 percent cut off. However for other clones like JC8 and G175-405 a lower cut off of 50 percent may be better (Shelton et al., 2017). We used the E6H4 clone (CINtec histology) of p16 antibody in the present study since it is the most widely used clone in studies of HPV associated cancers.

In this study we performed the HPV DNA PCR only on cases which were 16 immunopositive. This was done to look for transcriptionally active HPV infection which plays an important role in carcinogenesis. Episomal and transient HPV infections would also come HPV DNA PCR positive but these are not important in causation of head and neck carcinoma (Jung et al., 2010).

The main age group affected by OSCC was 40-60 years $(60.3 \%$ cases $)$ similar to previous studies on OSCC. However there was no correlation of age with $\mathrm{p} 16$ or HPV status similar to previous studies (Koppikar et al., 2005). HPV infection is generally acquired at the age of sexual debut and HPV associated malignancies generally peak two to three decades later.

Tobacco usage was the main risk factor for the development of OSCC (Jiang et al., 2019). Both smokeless tobacco (SLT) and tobacco smoking were identified as the main risk factor in the majority of the patients in this study. Interestingly the p16 positivity rates were similar in the patients who had never consumed tobacco and patients having tobacco habit. Since p16 immunoexpression can be upregulated by non HPV pathway as well, this result can be attributed to non HPV pathway. However the HPV PCR positivity in a similar proportion of patients breaks the myth that non tobacco users have a higher likelihood of HPV positivity. HPV has been the main culprit behind the recent rise in OPSCC patients in the western world since smoking cessation programs have reduced the incidence of tobacco related OPSCC. However the etiology of OSCC is vastly different and here HPV is likely to have a facilitating role in carcinogenesis (Liu et al., 2010).
The male to female ratio of OSCC patients in our study was 7.1:1. However similar proportions of male and female patients were found to be HPV PCR and p16 positive. This shows that gender does not affect the chances of p16 immunopositivity (Koppikar et al., 2005).

A higher positivity for $\mathrm{p} 16$ and HPV PCR was noted in the urban patients as opposed to the rural patients. ( $\mathrm{P}$ values $<0.001$ and 0.002 ) Possible reasons could be differences in the number of sexual partners of migrant workers in the cities. This study did not evaluate the effect of sexual practices and number of sexual partners on the p16 immunopositivity. Due to cultural taboos associated with this topic it is often difficult to obtain an accurate history related to oral sex. However previous studies have found a significant correlation between number of sexual partners, number of passionate kissing partners, oral sex, being married at some point of time and p16 immunopositivity in oropharyngeal squamous cell carcinoma (Emmett et al., 2018). At the same time other studies have refuted these claims (de C Ferreira et al., 2021).

Our study compared the 16 and HPV PCR positivity between married and unmarried patients but found no significant difference. A higher percentage of graduate and post graduate educated and illiterate patients were found to p16 and HPV DNA PCR positive. A similar relation to educational status has been reported for oropharyngeal squamous cell carcinoma (Emmett et al., 2018). Interestingly there was no correlation with the type of occupation of the patients.

There was no difference in the p16 immunopositivity of Muslim and non-Muslim patients. Male circumcision practiced by Muslims has been postulated to be beneficial in reducing the incidence of HPV driven cervical carcinomas in Muslim ladies (Morris et al., 2019). However we found no evidence of reduced p16 or HPV DNA positivity amongst the Muslims as compared to non-Muslim community.

The effect of diet on the causation of HPV associated cancers has received some attention recently. A healthy mediterranian type diet has shown a protective effect against cervical carcinoma (Barchitta et al., 2018). We found a higher percentage of vegetarians with p16 immunopositivity as opposed to patients having both vegetarian and non-vegetarian diets. There seems to be no plausible explanation for this finding. A more detailed analysis looking at micronutrients in the diet is needed to study the effect of dietary patterns.

No significant correlation was found for $\mathrm{p} 16$ /HPV status and site of the tumor in the oral cavity. These findings are in consonance with previous studies (Blahak et al., 2020). The higher percentage of p16 immunopositive tumors in the younger age group with no tobacco habits (Table 3 ) points towards the possibility of HPV being the primary carcinogen and not just a bystander or co-carcinogen in this subset of patients. Our findings are similar to previous studies on this topic (Dediol et al., 2016)

There was no statistically significant correlation between $\mathrm{p} 16$ / HPV positivity and the clinical stage or histological differentiation of the tumor. P16 
immunopositivity has been reported to be associated with poorer prognosis in OSCC in few studies while others have reported p16 loss to have a poorer prognosis (Pérez-Sayáns et al., 2015; Chen et al., 2012). Chen et al., (2012)reported that there is a trend towards the loss of p16 expression in higher $\mathrm{T}$ stages however this was found only in patients without lymph node metastasis. They reported p16 loss to be associated with poorer prognosis and a tendency for recurrence. In our study though a majority of OSCC patients with $\mathrm{p} 16 / \mathrm{HPV}$ positivity belonged to the stage IVA, the $\mathrm{p}$ value for $\mathrm{p} 16$ versus stage was found to be insignificant.

Caution is advised in interpreting the epidemiological studies on non oropharyngeal head and neck squamous cell carcinomas. HPV DNA and p16 immunohistochemistry both lack specificity and other methods like DNA-ISH and RNA-ISH and E6 and E7 antibody detection lack sensitivity for identifying HPV driven squamous cell carcinoma in non oropharyngeal head and neck sites. A significant number of oral squamous cell carcinomas were found to be $\mathrm{p} 16$ and HPV DNA PCR positive in this study. Most of the 16 and HPV DNA positive cases were tobacco/betel nut users. Whether HPV was the main driver of the neoplastic process or a cofactor in these cases needs further studies (Combes et al., 2014; Wang et al., 2020). However a higher percentage of p16 immunopositivity amongst younger patients with no tobacco habits points towards a distinct subset of patients in whom HPV may be the chief culprit and not just playing a supporting role.

\section{Author Contribution Statement}

Farhat Naz: Conceptualization, designed, investigation, data curation, analysis and writing of original manuscript draft. Hitesh Verma: methodology and manuscript review. Nadeem Tanveer: Conceptualization, designed, data analysis, and manuscript draft. Sudheer Arava: methodology and reviewing manuscript. Aanchal Kakkar: methodology and reviewing manuscript. Pranay Tanwar: methodology, analysis and reviewing manuscript.

\section{Acknowledgements}

We are thankful to all the participants for their support in the study. We are also grateful to the clinicians and non-clinical staff of the ENT Department in collecting biopsy sample of the patients from minor OT.

\section{Funding}

This study was supported by a Grant from the Government of India Ministry of Health and Family Welfare (Department of Health Research), New Delhi (File No.R.12013/03/2018-HR).

\section{Ethical Clearance}

The study was given clearance by the Institute

Ethics Committee for Human Research Ref. no. IEC-286/01.06.2018, RP-17/2018.

\section{Declaration of Competing Interest}

All the authors declare that they have no competing and conflict of interest.

\section{References}

Bouda M, Gorgoulis V, Kastrinakis N, et al (2000). "High Risk" HPV types are frequently detected in potentially malignant and malignant oral lesions, but not in normal oral mucosa. Mod Pathol, 13, 644-53.

Barchitta M, Maugeri A, Quattrocchi A, et al (2018). The association of dietary patterns with high-risk human papillomavirus infection and cervical cancer: A CrossSectional Study in Italy. Nutrients, 10, 469.

Blahak J, Zelinka J, Gumulec J, et al (2020). HPV, protein p16 and squamous cell carcinoma of the oral cavity. Biomed Pap Med Fac Univ Palacky Olomouc Czech Repub, 164, 292-9.

Chen YW, Kao SY, Yang MH (2012). Analysis of p16(INK4A) expression of oral squamous cell carcinomas in Taiwan: prognostic correlation without relevance to betel quid consumption. J Surg Oncol, 106, 149-54.

Combes JD, Franceschi S (2014). Role of human papillomavirus in non-oropharyngeal head and neck cancers. Oral Oncol, 50, 370-9.

de C Ferreira C, Dufloth R, de Carvalho AC, et al (2021). Correlation of p16 immunohistochemistry with clinical and epidemiological features in oropharyngeal squamous-cell carcinoma. PLoS One, 16, e0253418.

Dediol E, Sabol I, Virag M, et al (2016). HPV prevalence and p16INKa overexpression in non-smoking non-drinking oral cavity cancer patients. Oral Dis, 22, 517-22.

Emmett S, Boros S, Whiteman DC, et al (2018). Sexual behaviour, HPV status and p16INK4a expression in oropharyngeal and oral cavity squamous cell carcinomas: a case-case comparison study. J Gen Virol, 99, 783-9.

Gayatree A, Tanveer N, Arora VK, Arora V (2020). Are histomorphological features predictive of p16 immunopositivity different for oral and oropharyngeal squamous cell carcinoma?. Indian J Surg Oncol, 11, 248-55.

Jung AC, Briolat J, Millon R, et al (2010). Biological and clinical relevance of transcriptionally active human papillomavirus (HPV) infection in oropharynx squamous cell carcinoma. Int J Cancer, 126, 1882-94.

Jiang X, Wu J, Wang J, Huang R (2019). Tobacco and oral squamous cell carcinoma: A review of carcinogenic pathways. Tob Induc Dis, 17, 29.

Kato MG, Baek CH, Chaturvedi P, et al (2020). Update on oral and oropharyngeal cancer staging - International perspectives. World J Otorhinolaryngol Head Neck Surg, 6, 66-75.

Kreimer AR, Clifford GM, Boyle P, Franceschi S (2005). Human papillomavirus types in head and neck squamous cell carcinomas worldwide: a systematic review. Cancer Epidemiol Biomarkers Prev, 14, 467-75.

Koppikar P, deVilliers EM, Mulherkar R (2005). Identification of human papillomaviruses in tumors of the oral cavity in an Indian community. Int $J$ Cancer, 113, 946-50.

Laco J, Nekvindova J, Novakova V, et al (2012). Biologic importance and prognostic significance of selected clinicopathological parameters in patients with oral and oropharyngeal squamous cell carcinoma, with emphasis on smoking, protein p16(INK4a) expression, and HPV status. Neoplasma, 59, 398-408.

Liu SS, Leung RC, Chan KK, Cheung AN, Ngan HY (2010). Evaluation of a newly developed GenoArray human papillomavirus (HPV) genotyping assay and comparison with the Roche Linear Array HPV genotyping assay. J Clin Microbiol, 48, 758-64.

Machczyński P, Majchrzak E, Niewinski P, Marchlewska J, 
Golusiński W (2020). A review of the 8th edition of the AJCC staging system for oropharyngeal cancer according to HPV status. Eur Arch Otorhinolaryngol, 277, 2407-12.

Maléřová S, Kalfeřt D, Grega M, Tachezy R, Klozar J (2020). The significance of $\mathrm{p} 16$ protein expression in oral squamous cell carcinoma. Epidemiol Microbiol Imunol, 69, 64-72.

Mena M, Frias-Gomez J, Taberna M, et al (2020). Epidemiology of human papillomavirus-related oropharyngeal cancer in a classically low-burden region of southern Europe. Sci Rep, 10, 13219.

Morris BJ, Hankins CA, Banerjee J, et al (2019). Does male circumcision reduce women's risk of sexually transmitted infections, cervical cancer, and associated conditions?. Front Public Health, 7, 4.

Palve V, Bagwan J, Krishnan NM, et al (2018). Detection of high-risk human papillomavirus in oral cavity squamous cell carcinoma using multiple analytes and their role in patient survival. J Glob Oncol, 4, 1-33.

Panarese I, Aquino G, Ronchi A, et al (2019). Oral and Oropharyngeal squamous cell carcinoma: prognostic and predictive parameters in the etiopathogenetic route. Expert Rev Anticancer Ther, 19, 105-19.

Pérez-Sayáns M, Suárez-Peñaranda JM, Padín-Iruegas ME, et al (2015). The loss of $\mathrm{p} 16$ expression worsens the prognosis of OSCC. Appl Immunohistochem Mol Morphol, 23, 724-32.

Seraj JM, Yazdani N, Ashtiani ZO, et al (2011). TP53 gene expression in HPV-positive oral tongue SCC and its correlation with nodal metastasis. Pathol Res Pract, 207, 758-61.

Shelton J, Purgina BM, Cipriani NA, et al (2017). p16 immunohistochemistry in oropharyngeal squamous cell carcinoma: a comparison of antibody clones using patient outcomes and high-risk human papillomavirus RNA status. Mod Pathol, 30, 1194-1203.

Wang F, Zhang H, Xue Y,et al (2017). A systematic investigation of the association between HPV and the clinicopathological parameters and prognosis of oral and oropharyngeal squamous cell carcinomas. Cancer Med, 6, 910-17.

Wang H, Zhang Y, Bai W, et al (2020). Feasibility of immunohistochemical p16 staining in the diagnosis of human papillomavirus infection in patients with squamous cell carcinoma of the head and neck: A Systematic Review and Meta-Analysis. Front Oncol, 10, 524928.

This work is licensed under a Creative Commons AttributionNon Commercial 4.0 International License. 